\title{
Analisis Perbandingan Efisiensi Daya Modified Sine Inverter Dengan Pure Sine Inverter
}

\author{
Fariz Yulianto $^{1}$, Wakhyu Dwiono ${ }^{2}$, Winarso $^{3}$ \\ Program Studi S1 Teknik Elektro, Universitas Muhammadiyah Purwokerto \\ Fakultas Teknik dan Sains, Universitas Muhammadiyah Purwokerto
}

\begin{tabular}{l} 
Informasi Makalah \\
\hline Dikirim, 8 Mei 2019 \\
Direvisi, 1 Juli 2019 \\
Diterima, \\
\\
\hline
\end{tabular}

\section{Kata Kunci:}

Inverter

Uninterruptible Power Suplay (UPS)

Efisiensi Daya

\section{INTISARI}

Penyimpangan daya seperti adanya gangguan listrik dapat menyebabkan dampak yang parah pada beban yang sensitif atau penting dalam sistem kelistrikan, sehingga dibutuhkan peralatan pendukung yang berfungsi untuk tetap tersedianya kualitas daya yang baik. Salah satu peralatan pendukung yang dapat melindungi berbagai perangkat vital dari gangguan adalah Uninnteruptible Power Supply (UPS) dan Inverter, alat ini berfungsi sebagai stabilizer terhadap gangguan dan menjadi sumber daya cadangan. Inverter adalah rangkaian yang mengubah arus searah (DC) menjadi arus bolak-balik (AC), inverter sangat berperan penting sebagai salah satu komponen penyedia listrik baik dikendaraan maupun dirumah sebagai emergency power saat aliran listrik padam. Penelitian ini bertujuan untuk mengetahuai berapa besar perbandingan efisiensi daya yang dihasilkan inverter dengan UPS (Uninnteruptible Power Supply) dan untuk mengetahui bentuk gelombang output dari (Uninnteruptible Power Supply) dan bentuk gelombang output dari inverter, metode yang digunakan dalam penelitian ini yaitu menguji dengan berbagai macam beban. Hasil dari analisis dari perbandingan efisiensi daya modified sine invertre (MSI) dengan pure sine inverter (PSI) pada pengukuran menggunakan beban resistfif efisiensi daya lebih baik menggunakan UPS, untuk pengukuran beban induktif efisiensi daya lebih baik menggunakan inverter, dan pengukuran beban menggunakan beban kapasitif efisiensi daya lebih baik menggunakan inverter, bentuk gelombang keluaran pada modified sine invertre (MSI) dipengaruhi oleh beban pengukuran dan berbetuk gelombang kotak termodifikasi sedangkan bentuk gelombang keluaran pada pure sine inverter (PSI) tidak dipengaruhi oleh beban pengukuran dan berbentuk gelombang sinus murni.

\section{Keyword:}

Inverters, Uninterruptible

Power Suplay (UPS),

Efficiency of Power

\begin{abstract}
Power devations such as power failures can cause severe impacts on sensitive or important loads in electrical systems. Therefore, it requires supporting tools that serve to maintain good power quality. One of the supporting tools that can protect the various vital devices from interference is Uninterruotible Power supply (UPS) and Inverter. This tool also serves as a stabilizer against interference and as a backup resource. Inverter ia a circuit that converts direct current (DC) into alternating current (AC). The inverter has a very important role as oneof thecomponents of electricity providers used for vehicles and as emergencypower at home during the power outages. The aim of this research is to measure the power efficiency ratio resulted from inverter and from UPS (Uninterrubtible Power Supply)and to know the output waveform from both UPS (Uninterrubtible Power Supply) and inverter. Testing various loads is the method in this study. The results of the study on a comparative analysis of power efficiency between modified sine inverter (MSI) and pure sine inverter (PSI) revealed that using UPS ws much better on measurement by resistant power efficiency, using inverter was found betterfor inductive load measurement of power efficiency, and using inverter was also better for load measurement using capacitive load efficiency. This study also resulted that the output wavefrom in modified sine inverter (MSI)
\end{abstract}


was affected by the measurement load and modified in box wavefrom, in addition, the wavefrom output in the pure sine inverter (PSI) was not affect by the measurement load with pure sine waveform.

\section{Korespondensi Penulis:}

Fariz Yulianto

Program Studi S1 Teknik Elektro

Universitas Muhammadiyah Purwokerto

Jl. Raya Dukuh Waluh Purwokerto, 53182

Email: fariz_yulianto@gmail.com

\section{PENDAHULUAN}

Penyimpangan daya seperti adanya gangguan listrik dapat menyebabkan dampak yang parah pada beban yang sensitif atau penting dalam sistem kelistrikan. Sistem Uninterruptible Power Supply atau yang disingkat UPS dapat diandalkan dalam mengalirkan daya ke beban yang sensitif tanpa terputus dan memiliki kualitas daya yang tinggi sehinggga dampak tersebut dapat dikurangi.

Selama gangguan listrik terjadi, UPS menyediakan daya cadangan menjaga sistem peralatan listrik pada beban untuk tetap berjalan dalam waktu yang cukup lama, sehingga sistem peralatan listrik pada beban tersebut dapat dimatikan secara normal. Dalam UPS, sarana penyimpanan energi listrik (Energi Storage) umumnya adalah baterai, terdapat dua pengubah tegangan yaitu penyearah (rectifier) dan Inverter. (Adel Nasiri, $2011: 627)$.

Penyearah (Rectifier) merupakan pengubah tegangan masukan AC menjadi DC. Catu daya DC tersebut bertugas mengisi energi listrik ke dalam baterai (Energi Storage), sedangkan inverter memberikan fungsi tegangan keluaran berupa AC dari masukan sumber tegangan DC yang dihasilkan oleh baterai untuk penggunaan kebutuhan beban (Critical Load). Inverter ini sangat berperan penting sebagai salah satu komponen baik dikendaraan maupun dirumah, sebagai emergency power saat aliran listrik padam. Selain itu dimasa mendatang, inverter DC ke AC akan memegang peranan penting dalam mengubah energi DC dari sumber energi terbarukan sel surya menjadi energi listrik AC yang kita gunakan sehari-hari (A.E.Fitzgerald, 1985 : 394).

\section{METODE PENELITIAN}

Objek penelitian adalah UPS (Uninterruptible Power Supply) dan Pure Sine Wave Inverter dengan pengukuran beban daya maksimal 500 Watt, pengujian dan analisis sistem dengan acuan uji pengukuran tanpa beban, uji beban resistif, uji beban induktif dan uji beban kapasitif. Dalam penyusunan penelitian ini metode yang digunakan dalam menyelesaikan penelitian diantaranya:

\subsection{Metode Kepustakaan}

Metode ini dilakukan dengan cara mengambil dan mempelajari data-data dari buku- buku literature sebagai acuan untuk mendukung terselesainya penelitian agar lebih terarah

\subsection{Metode observasi}

Metode ini dilakukan dengan cara pengumpulan data melalui pengukuran maupun pengamatan suatu obyek yang sedang diamati dan diteliti, kemudian dianalisa apabila ada perbedaan dengan data acuan dalam usaha melengkapi penyusunan skripsi. 


\subsection{Metode Interview}

Metode ini diterapkan apabila mengalami kesulitan dalam memahami data-data yang dipelajari, yaitu dengan cara berkonsultasi kepada pembimbing maupun orang lain yang lebih mengerti mengenai pembahasan yang sedang dikemukakan.

\section{HASIL DAN PEMBAHASAN}

\subsection{Hasil pengukuran tanpa beban pada Pure Sine Inverter}

Pengukuran tanpa menggunakan beban pada Inverter diperoleh data yang ditampilkan pada Table 3.1 Hasil pengukuran tanpa menggunakan beban pada Inverter :

Tabel 3.1. Hasil pengukuran tanpa menggunakan beban pada Inverter

\begin{tabular}{ccc}
\hline & Pin (DC) \\
\hline $\mathrm{P}(\mathrm{W})$ & $\mathrm{V}(\mathrm{v})$ & $\mathrm{I}(\mathrm{A})$ \\
60 & 24 & 2,5
\end{tabular}

Keterangan :

1. $\mathrm{V}=$ Tegangan $($ Volt $)$

2. $\mathrm{I}=$ Arus (Ampere)

3. $\mathrm{P}(\mathrm{P} . \mathrm{in})=$ Hasil daya dari perkalian $\mathrm{V} \times \mathrm{I}(\mathrm{Watt})$

Hasil pengukuran tanpa menggunakan beban pada Inverter tegangan pada P.in sebesar $24 \mathrm{~V}$ dengan arus 2,5 A menghasilkan daya sebesar $60 \mathrm{~W}$. Pengukuran inverter tanpa menggunakan beban menghasilkan daya sebesar $60 \mathrm{~W}$, dengan tegangan $24 \mathrm{~V}$, dan arus 2,5 A bentuk gelombang yang dihasilkan adalah gelombang sinus murni dengan frekuensi $50 \mathrm{~Hz}$ dan ditampilkan pada Gambar 2 bentuk gelombang sinus hasil pengukuran pada inverter tanpa menggunakan beban

Hasil pengukuran tanpa beban pada UPS (Uninterrubtible Power Supply) Pengukuran tanpa menggunakan beban pada UPS diperoleh data yang ditampilkan

pada Tabel 3.2 Hasil pengukuran tanpa menggunakan beban pada UPS (Uninterrubtible Power Supply):

Tabel 3.2 Hasil pengukuran tanpa menggunakan beban pada UPS (Uninterrubtible Power Supply)

\begin{tabular}{ccc}
\hline \multicolumn{3}{c}{ Pin $(\mathrm{DC})$} \\
\hline $\mathrm{P}(\mathrm{W})$ & $\mathrm{P}(\mathrm{W})$ & $\mathrm{P}(\mathrm{W})$ \\
60 & 24 & 2,5
\end{tabular}

Keterangan :

1. $\mathrm{V}=$ Tegangan $($ Volt $)$

2. $\mathrm{I}=$ Arus (Ampere)

3. $\mathrm{P}(\mathrm{P} . \mathrm{in})=$ Hasil daya dari perkalian $\mathrm{V} \times \mathrm{I}($ Watt $)$

Hasil pengukuran tanpa menggunakan beban pada UPS tegangan pada P.in sebesar $24 \mathrm{~V}$ dengan arus 2,5 A menghasilkan daya sebesar $60 \mathrm{~W}$. Gelombang output yang dihasilkan dari pengukuran UPS tanpa menggunakan beban dengan frekuensi $50 \mathrm{~Hz}$ adalah gelombang kotak yang ditampilkan pada Gambar 4.2 Bentuk gelombang kotak hasil pengukuran pada UPS tanpa menggunakan beban 


\subsection{Hasil pengukuran beban resistif}

Pengukuran beban resistif pada inverter menggunakan beban lampu pijar dengan beban $40 \mathrm{~W}, 60$ $\mathrm{W}, 100 \mathrm{~W}, 140 \mathrm{~W}$, dan $200 \mathrm{~W}$ maka data yang dihasilkan pada Tabel 3.3 Hasil Pengukuran lampu pijar pada Inverter:

Tabel 3.3 Hasil Pengukuran lampu pijar pada Inverter

\begin{tabular}{cccccccc}
\hline & Pin $(\mathrm{DC})$ & \multicolumn{5}{c}{ Pout (AC) } \\
\hline Beban & $\mathrm{P}(\mathrm{W})$ & $\mathrm{V}(\mathrm{v})$ & $\mathrm{I}(\mathrm{A})$ & $\mathrm{P}(\mathrm{W})$ & $\mathrm{V}(\mathrm{v})$ & $\mathrm{I}(\mathrm{A})$ & $\eta(\%)$ \\
$40 \mathrm{~W}$ & 62 & 24,8 & 2,5 & 36 & 223,6 & 0,18 & 58 \\
$60 \mathrm{~W}$ & 73,8 & 24,6 & 3 & 52 & 222,7 & 0,27 & 70 \\
$100 \mathrm{~W}$ & 115,9 & 24,4 & 4,75 & 68 & 224,1 & 0,46 & 58 \\
$100+40=140 \mathrm{~W}$ & 134,9 & 24,1 & 5,6 & 105 & 222,5 & 0,575 & 77 \\
$100+60=160 \mathrm{~W}$ & 180,7 & 24,1 & 7,5 & 122 & 222,1 & 0,575 & 67 \\
$200 \mathrm{~W}$ & 238 & 23,8 & 10 & 156 & 222,1 & 0,58 & 65 \\
\hline
\end{tabular}

Keterangan :

1. $\mathrm{V}=$ Tegangan (Volt)

2. $\mathrm{I}=$ Arus (Ampere)

3. $\eta=$ Efisiensi daya $(\%)$

4. $\mathrm{P}(\mathrm{P} . \mathrm{in})=$ Hasil daya dari perkalian $\mathrm{V} \times \mathrm{I}(\mathrm{Watt})$

5. $\mathrm{P}(\mathrm{P}$.out $)=$ Hasil daya dari Alat ukur Wattmeter

Hasil pengukuran beban resistif lampu pijar pada inverter, dengan beban $40 \mathrm{~W}$ pada Pin adalah arus DC dengang tegangan 24,8 V dan arus 2,5 A dihasilkan daya P sebesar $62 \mathrm{~W}$ dan hasil Pout AC dihasilkan tegangan sebesar 223,6 V dengan arus 0,18 A dan daya pada Pout hasil dari alat ukur wattmeter sebesar 36 $\mathrm{W}$ dengan efisiensi daya $58 \%$. Sedengkan pada beban $60 \mathrm{~W}$ pada Pin tegangan turun menjadi 24,6 V dan arus naik menjadi $3 \mathrm{~A}$, dan pada Pout tegangan menjadi 222,7 V dengan arus 0,27 A, hasil daya dari alat ukur sebesar $52 \mathrm{~W}$ dengan efisiensi daya sebesar 70\%. Pada beban $100 \mathrm{~W}$ tegangan pada P.in 24,4 V dan arus 4,75 A menghasilkan daya P sebesar 115,9 W, dan tegangan pada Pout 224,1 V dengan arus 0,46 A, daya P dari alat ukur $68 \mathrm{~W}$ dengan efisiensi daya 58\%. Pada beban $140 \mathrm{~W}$ tegangan pada Pin dihasilkan $24,1 \mathrm{~V}$ dengan arus 5,6 A menghasilkan daya P sebesar 134,9 W, pada Pout menghasilkan tegangan sebesar 222,5 $\mathrm{V}$ dengan arus $0,575 \mathrm{~A}$ menghasilkan daya $\mathrm{P}$ dari alat ukur $105 \mathrm{~W}$ dengan efisiensi daya $77 \%$. Pada beban $160 \mathrm{~W}$ menghasilkan tegangan pada Pin sebesar 24,1 V dan arus 7,5 A menghasilkan daya P sebesar 180,7 W, sedangkan pada Pout teganggan menghasilkan 222,1 V dan arus sebesar 0,575 A, daya P hasil alat ukur sebesar $122 \mathrm{~W}$ dengan efisiensi daya 67\%. Sedangkan pada beban lampu $200 \mathrm{~W}$ tegangan pada P.in sebesar 23,8 V dengan arus 10 A menghasilkan daya P sebesar $238 \mathrm{~W}$, sedangkan pada Pout menghasilkan tegangan sebesar 222,1 V dan arus 0,58 A, daya P hasil dari alat ukur sebesar $156 \mathrm{~W}$, dengan efisiensi daya $65 \%$.

Gelombang output dari pengukuran beban resisitif dengan berbagai macam beban menggunakan inverter, gelombang yang dihasilkan adalah gelombang sinus murni dan bentuk gelombang tidak dipengaruhi oleh berbagai macam beban pengukuran.

Pengukuran beban resistif pada UPS menggunakan beban lampu pijar dengan beban $40 \mathrm{~W}, 60 \mathrm{~W}$, $100 \mathrm{~W}, 140 \mathrm{~W}$, dan $200 \mathrm{~W}$ maka data yang dihasilkan pada Tabel 3.4 Hasil Pengukuran lampu pijar Pada UPS (Uninterruptible Power Supply) :

Halaman Web JRRE : http://jurnalnasional.ump.ac.id/index.php/JRRE 
Tabel 3.4 Hasil Pengukuran lampu pijar Pada UPS (Uninterruptible Power Supply)

\begin{tabular}{cccccccc}
\hline & Pin (DC) & \multicolumn{5}{c}{ Pout (AC) } \\
\hline Beban & P (W) & V (v) & I (A) & P (W) & V (v) & I (A) & $\eta(\%)$ \\
$40 \mathrm{~W}$ & 64,39 & 24,3 & 2,65 & 50 & $183, .9$ & 0,175 & 77 \\
$60 \mathrm{~W}$ & 91,12 & 24,3 & 3,75 & 61 & 185,1 & 0,265 & 66 \\
$100 \mathrm{~W}$ & 144 & 24,0 & 6 & 110 & 192,5 & 0,41 & 76 \\
$100+40=140 \mathrm{~W}$ & 189,6 & 23,7 & 8 & 145 & 11,5 & 0,51 & 76 \\
$100+60=160 \mathrm{~W}$ & 235 & 23,5 & 10 & 165 & 11,32 & 0,515 & 70 \\
$200 \mathrm{~W}$ & 278,4 & 23,2 & 12 & 199 & 10,9 & 0,6 & 71 \\
\hline
\end{tabular}

Keterangan :

1. $\mathrm{V}=$ Tegangan (Volt)

2. $\mathrm{I}=$ Arus (Ampere)

3. $\eta=$ Efisiensi daya $(\%)$

4. $\mathrm{P}(\mathrm{Pin})=$ Hasil daya dari perkalian $\mathrm{V} \times \mathrm{I}($ Watt $)$

5. $\mathrm{P}($ Pout $)=$ Hasil daya dari Alat ukur Wattmeter

Hasil pengukuran beban resistif lampu pijar pada UPS, dengan beban $40 \mathrm{~W}$ pada Pin adalah arus DC dengang tegangan 24,3 V dan arus 26,5 A dihasilkan daya P sebesar 64,39 W dan hasil Pout AC dihasilkan tegangan sebesar 183,9 V dengan arus 0,175 A dan daya P pada P.out hasil dari alat ukur wattmeter sebesar $50 \mathrm{~W}$ dengan efisiensi daya $77 \%$. Sedengkan pada beban $60 \mathrm{~W}$ pada Pin tegangan setabil 24,3 V dan arus naik menjadi 3,75 A, pada Pout tegangan menjadi 185,1 V dengan arus 0,265 A,daya P hasil dari alat ukur sebesar $61 \mathrm{~W}$ dengan efisiensi daya sebesar 66\%. Pada beban 100 watt tegangan pada P.in 24,0 $\mathrm{V}$ dan arus 6 A menghasilkan daya P sebesar $144 \mathrm{~W}$, dan tegangan pada P.out 192,5 V dengan arus 0,41 A, daya $\mathrm{P}$ dari alat ukur $110 \mathrm{~W}$ dengan efisiensi daya $76 \%$. Pada beban $140 \mathrm{~W}$ tegangan pada Pin dihasilkan 23,7 V dengan arus 8 A menghasilkan daya P sebesar 189,6 W, pada Pout menghasilkan tegangan sebesar 11,5 V dengan arus 0,51 A menghasilkan daya $\mathrm{P}$ dari alat ukur $145 \mathrm{~W}$ dengan efisiensi daya $76 \%$. Pada beban $160 \mathrm{~W}$ menghasilkan teganga pada Pin sebesar 23,5 V dan arus 10 A dan daya P sebesar $235 \mathrm{~W}$, sedangkan pada Pout teganggan menghasilkan 11,32 V dan arus sebesar 0,515 A, daya P hasil alat ukur sebesar $165 \mathrm{~W}$ dengan efisiensi daya $70 \%$. Sedangkan pada beban lampu $200 \mathrm{~W}$ tegangan pada Pin sebesar 23,2 V dengan arus 12 A menghasilkan daya $\mathrm{P}$ sebesar 278,4 W, sedangkan pada Pout menghasilkan tegangan sebesar 10,9 V dan arus 0,6 A, daya P hasil dari alat ukur sebesar $199 \mathrm{~W}$, dengan efisiensi daya $71 \%$.

Gelombang output dari pengukuran beban resisitif dengan berbagai macam beban menggunakan UPS, gelombang yang dihasilkan adalah gelombang kotak termodifikasi atau gelombang kotak nois dengan bentuk gelombang dipengaruhi oleh berbagai macam beban pengukuran

\subsection{Hasil Pengukuran Beban Induktif}

Pengukuran beban induktif pada UPS menggunakan beban kipas angin maka data yang dihasilkan pada Tabel 3.5 Hasil pengukuran kipas angin dengan mode 3 kecepatan pada UPS :

Tabel 3.5 Hasil pengukuran kipas angin dengan mode 3 kecepatan pada UPS

\begin{tabular}{cccccccc}
\hline \multicolumn{3}{c}{ P.in (DC) } & \multicolumn{5}{c}{ P.out (AC) } \\
\hline Beban & $\mathrm{P}(\mathrm{W})$ & $\mathrm{V}(\mathrm{v})$ & $\mathrm{I}(\mathrm{A})$ & $\mathrm{P}(\mathrm{W})$ & $\mathrm{V}(\mathrm{v})$ & $\mathrm{I}(\mathrm{A})$ & $\eta(\%)$ \\
1 & 72,9 & 24,3 & 3 & 52 & 186,9 & 0,2 & 71 \\
2 & 72,9 & 24,3 & 3 & 53 & 184,7 & 0,205 & 72 \\
3 & 72,9 & 24,3 & 3 & 56 & 183,4 & 0,21 & 76 \\
\hline
\end{tabular}


Keterangan :

1. $\mathrm{V}=$ Tegangan (Volt)

2. $\mathrm{I}=$ Arus (Ampere)

3. $\eta=$ Efisiensi daya $(\%)$

4. $\mathrm{P}(\mathrm{Pin})=$ Hasil daya dari perkalian $\mathrm{V} \times \mathrm{I}(\mathrm{Watt})$

5. $\mathrm{P}($ Pout $)=$ Hasil daya dari Alat ukur Wattmeter

Hasil pengukuran beban induktif menggunakan kipas angin dengan tiga kecepatan pada UPS, pada kecepatan pertama atau beban 1 tegangan di Pin sebesar 24,3 V dengan arus

3 A dan menghasilkan daya sebesar 72,9 W, sedangkan tegangan pada Pout yaitu 186,9 V dengan arus 0,2 A dan daya efisiensi dayanya 71\%. Sedangkan pada kecepatan 2 tegangan Pin setabil pada 24,3 V dan arus ikut setabil 3 A dan menghasilkan daya sebesar 72,9 W, tegangan di Pout turun menjadi 184,7 V dan arus 0,205 A dan hasil daya dari alat ukur sebesar $53 \mathrm{~W}$, menghasilkan efisiensi daya sebesar $72 \%$. Pada kecepatan 3 atau beban yang nomor 3 tegangan Pin juga setabil pada 24,3 V dan arus juga setabil di 3 A dan menghasilkan daya sebesar 72,9 W, tegangan pada Pout turun menjadi $183,4 \mathrm{~V}$ dengan arus 0,21 A, dan daya hasil dari alat ukur sebesar $56 \mathrm{~W}$, dengan efisiensi sebesar $76 \%$.

Gelombang output dari pengukuran beban induktif dengan beban kipas angin menggunakan UPS, gelombang yang dihasilkan adalah gelombang kotak termodifikasi atau gelombang kotak nois dengan bentuk gelombang dipengaruhi oleh berbagai macam beban pengukuran

Pengukuran beban induktif pada inverter menggunakan beban kipas angin maka data yang dihasilkan pada Tabel 3.6 Hasil pengukuran kipas angin dengan mode 3 kecepatan padaInverter:

Tabel 3.6 Hasil pengukuran kipas angin dengan mode 3 kecepatan pada Inverter

\begin{tabular}{cccccccc}
\hline \multicolumn{4}{c}{ P.in (DC) } & \multicolumn{4}{c}{ P.out (AC) } \\
\hline Beban & $\mathrm{P}(\mathrm{W})$ & $\mathrm{V}(\mathrm{v})$ & $\mathrm{I}(\mathrm{A})$ & $\mathrm{P}(\mathrm{W})$ & $\mathrm{V}(\mathrm{v})$ & $\mathrm{I}(\mathrm{A})$ & $\eta(\%)$ \\
1 & 61 & 24,4 & 2,5 & 36 & 224,2 & 0,19 & 59 \\
2 & 61 & 24,4 & 2,5 & 39 & 223,8 & 0,2 & 63 \\
3 & 61 & 24,4 & 2,5 & 43 & 223,1 & 0,21 & 70 \\
\hline
\end{tabular}

Keterangan :

1. $\mathrm{V}=$ Tegangan (Volt)

2. $\mathrm{I}=$ Arus (Ampere)

3. $\eta=$ Efisiensi daya $(\%)$

4. $\mathrm{P}(\mathrm{Pin})=$ Hasil daya dari perkalian $\mathrm{V} \times \mathrm{I}(\mathrm{Watt})$

5. $\mathrm{P}($ Pout $)=$ Hasil daya dari Alat ukur Wattmeter

Hasil pengukuran beban induktif menggunakan kipas angin dengan tiga kecepatan pada Inverter, pada kecepatan pertama atau beban 1 tegangan di Pin sebesar 24,4 V dengan arus 2,5 A dan menghasilkan daya sebesar $61 \mathrm{~W}$, sedangkan tegangan pada Pout yaitu 224,2 V dengan arus 0,19 A dan daya dari hasil alat ukur sebesa $36 \mathrm{~W}$, efisiensi dayanya 59\%. Sedangkan pada kecepatan 2 tegangan Pin setabil pada 24,4 $\mathrm{V}$ dan arus ikut setabil 2,5 A dan menghasilkan daya sebesar $61 \mathrm{~W}$, tegangan di Pout turun menjadi 223,8 V dan arus 0,2 A dan hasil daya dari alat ukur sebesar $39 \mathrm{~W}$, menghasilkan efisiensi daya sebesar 63\%. Pada kecepatan 3 atau beban yang nomor 3 tegangan Pin juga setabil pada 24,4 V dan arus juga setabil di 2,5 A dan menghasilkan daya sebesar $61 \mathrm{~W}$, tegangan pada Pout turun menjadi

223,1 V dengan arus 0,21 A, dan daya hasil dari alat ukur sebesar $43 \mathrm{~W}$, dengan efisiensi sebesar $70 \%$.

Halaman Web JRRE : http://jurnalnasional.ump.ac.id/index.php/JRRE 
Gelombang output dari pengukuran beban induktif dengan beban kipas angin pada inverter, gelombang yang dihasilkan adalah gelombang sinus murni dan bentuk gelombang tidak dipengaruhi oleh berbagai macam beban pengukuran.

\subsection{Hasil Pengukuran Beban Kapasitif}

Pengukuran beban kapasitif pada UPS menggunakan beban lampu TL dengan beban $18 \mathrm{~W}, 36 \mathrm{~W}$, $54 \mathrm{~W}$, maka data yang dihasilkan pada Tabel 3.7 Hasil pengukuran lampu TL pada UPS :

Tabel 3.7 Hasil pengukuran lampu TL pada UPS

\begin{tabular}{cccccccc}
\hline \multicolumn{1}{c}{ Pin (DC) } & \multicolumn{5}{c}{ Pout (AC) } \\
\hline Beban & $\mathrm{P}(\mathrm{W})$ & $\mathrm{V}(\mathrm{v})$ & $\mathrm{I}(\mathrm{A})$ & $\mathrm{P}(\mathrm{W})$ & $\mathrm{V}(\mathrm{v})$ & $\mathrm{I}(\mathrm{A})$ & $\eta(\%)$ \\
$18 \mathrm{~W}$ & 61 & 24,4 & 2,5 & 22 & 181,1 & 0,29 & 36 \\
$36 \mathrm{~W}$ & 85 & 24,3 & 3,5 & 41 & 187,3 & 0,365 & 48 \\
$18+36=54 \mathrm{~W}$ & 132 & 24 & 5,5 & 62 & 193,1 & 0,51 & 46 \\
\hline
\end{tabular}

Keterangan :

1. $\mathrm{V}=$ Tegangan (Volt)

2. $\mathrm{I}=$ Arus (Ampere)

3. $\eta=$ Efisiensi daya $(\%)$

4. $\mathrm{P}(\mathrm{Pin})=$ Hasil daya dari perkalian $\mathrm{V} \times \mathrm{I}(\mathrm{Watt})$

5. $P($ Pout $)=$ Hasil daya dari Alat ukur Wattmeter

Dari hasil pengukuran lampu TL pada beban 18 watt tegangan pada baterai P.in 24,4 V dengan arus 2,5 ampere menghasilkan daya sebesar 61 watt, sedangkan tegangan keluaran pada Pout sebesar 181,1 V dengan arus 0,29 A, hasil daya pada alat ukur sebesar 22 watt menghasilkan efisiensi daya 36\%. Sedangkan menggunakan beban 36 watt tegangan Pin pada baterai turun menjadi 24,3 V dengan arus naik menjadi 3,5 ampere dan penghasilkan daya $85 \mathrm{~W}$, sedangkan tegangan keluaran pada Pout naik menjadi 187,3 V dengan arus $0,365 \mathrm{~A}$, daya hasil dari alat ukur $41 \mathrm{~W}$ dan dengan efisiensi daya $48 \%$. Pada beban $54 \mathrm{~W}$ tegangan baterai Pin turun menjadi $24 \mathrm{~V}$ dengan arus naik menjadi 5,5 A dan menghasilkan daya $132 \mathrm{~W}$, sedangkan tegangan padda Pout naik menjadi 193,1 V dan arus 0,51 A, hasil daya dari alat ukur $62 \mathrm{~W}$, menghasilkan efisiensi daya $46 \%$.

Gelombang output dari pengukuran beban kapasitif dengan beban lampu TL menggunakan UPS, gelombang yang dihasilkan adalah gelombang kotak termodifikasi atau gelombang kotak nois dengan bentuk gelombang dipengaruhi oleh berbagai macam beban pengukuran. Pengukuran beban kapasitif pada inverter menggunakan beban lampu TL dengan beban $18 \mathrm{~W}, 36 \mathrm{~W}, 54 \mathrm{~W}$, maka data yang dihasilkan pada Tabel 3.8 Hasil pengukuran lampu TL pada inverter :

Tabel 8 Hasil pengukuran lampu TL pada inverter

\begin{tabular}{cccccccc}
\hline \multicolumn{3}{c}{ Pin (DC) } & \multicolumn{5}{c}{ Pout (AC) } \\
\hline Beban & $\mathrm{P}(\mathrm{W})$ & $\mathrm{V}(\mathrm{v})$ & $\mathrm{I}(\mathrm{A})$ & $\mathrm{P}(\mathrm{W})$ & $\mathrm{V}(\mathrm{v})$ & $\mathrm{I}(\mathrm{A})$ & $\eta(\%)$ \\
$18 \mathrm{~W}$ & 36 & 24,4 & 1,5 & 24 & 224,9 & 0,31 & 66 \\
$36 \mathrm{~W}$ & 60 & 24,3 & 2,5 & 35 & 223,4 & 0,35 & 58 \\
$18+36=54 \mathrm{~W}$ & 72 & 24 & 3 & 54 & 221,9 & 0,51 & 75 \\
\hline
\end{tabular}


Keterangan :

1. $\mathrm{V}=$ Tegangan (Volt)

2. $\mathrm{I}=$ Arus (Ampere)

3. $\eta=$ Efisiensi daya $(\%)$

4. $\mathrm{P}(\mathrm{Pin})$ daya $=$ Hasil daya dari perkalian $\mathrm{V} \times \mathrm{I}(\mathrm{Watt})$

5. $\mathrm{P}$ (Pout) daya $=$ Hasil daya dari alat ukur Wattmeter (Watt)

Hasil pengukuran lampu TL menggunakan Inverter pada beban $18 \mathrm{~W}$ tegangan baterai pada Pin sebesar 24,4 V dengan arus 1,5 A menghasilkan daya $36 \mathrm{~W}$, sedangkan keluaran tegangan pada Pout 224,9 $\mathrm{V}$ dan arus menjadi 0,31 A daya yang dihasilkan dari alat ukur sebesar $24 \mathrm{~W}$, menghasilkan efisiensi daya sebesar 66\%. Pada beban $36 \mathrm{~W}$ tegangan baterai Pin turun menjadi 24,3 V dengan arus naik menjadi 2,5 A menghasilkan daya sebesar60 W, sedangkan tegangan keluaran pada Pout ikut turun menjadi 223,4 V dan arus $0,35 \mathrm{~A}$, hasil daya dari alat ukur menunjukan $35 \mathrm{~W}$, menghasilkan efisiensi daya $58 \%$. Sedangkan pada beban $54 \mathrm{~W}$ tegangan baterai pada Pin turun menjadi $24 \mathrm{~V}$ dengan arus naik menjadi $3 \mathrm{~A}$ menghasilkan daya sebesar $72 \mathrm{~W}$. Sedangkan tegangan pada Pout turun menjadi 221,9 V dengan arus 0,51 A hasil daya dari alat ukur sebesar $54 \mathrm{~W}$, dengan efisiensi daya sebesar $75 \%$.

Gelombang output dari pengukuran beban kapasitif dengan beban lampu TL pada inverter, gelombang yang dihasilkan adalah gelombang sinus murni dan bentuk gelombang tidak dipengaruhi oleh berbagai macam beban pengukuran.

\section{KESIMPULAN}

Dari hasil penelitian analisis perbandingan efisiensi daya modified sine inverter dengan pure sine inverter diperoleh hasil mulai dari tahap perancangan hingga tahap pengujian alat sehingga dapat ditarik kesimpulan serta diajukan saran-saran untuk penelitian selanjutnya. Kesimpulan dan saran dalam skripsi ini sebagai berikut:

a. Dari hasil pengukuran pada Inverter bentuk keluaran gelombang output berbentuk sinus murni untuk semua jenis beban pengukuran.

b. Hasil dari pengukuran menggunakan UPS (Uninterruptible Power Supply) bentuk keluaran gelombang outputnya berbentuk gelombang kotak termodifikasi dan untuk masing-masing beban berbeda bentuk gelombang.

c. Dari hasil analisis pada pengukuran menggunakan beban lampu pijar efisiensi daya lebih Bik menggunakan UPS yaitu $72 \%$, lampu hemat energi dikombinasikan dengan lampu pijar didapatkan efisiensi daya lebih tinggi menggunakan inverter yaiutu $71 \%$, sedangkan jenis beban lampu kombinsai antara lampu LED dengan lampu pijar lebih baik menggunakan inverter yaitu $80 \%$, dan lampu TL efisiensi daya lebih bagus menggunakn inverter yaitu $66 \%$

d. Dari hasil analisis data pada pengukuran beban menggunakan kipas angin efisiensi daya lebih bagus menggunakan UPS yaitu $73 \%$, dibandingkan menggunakan Inverter yaitu $64 \%$

e. Dari hasil analisis data pada pengukuran bor listrik menggunakan beban efisiensi daya setabil antara menggunakan UPS dengan Inverter yaitu 87\%, dan pada pengukuran bor listrik tanpa menggunakan beban pada Inverter dan UPS setabil yaitu $85 \%$.

\section{DAFTAR PUSTAKA}

[1] Fitzgerald, A.E. et al. 1985. Dasar-dasar Elektronik Jilid 2. Jakarta: Erlangga.

[2] Nasiri, Adel. 2011. Power Electronics Handbook (3 ed.). Muhammad H. Rashid (ed.). Hlm.627-641.

Halaman Web JRRE : http://jurnalnasional.ump.ac.id/index.php/JRRE 